\title{
People Participation Towards Opisthorchis viverrini Prevention and Control in Chaiyaphum Province, Northeastern Thailand
}

\author{
Rutjirapat Phongsiripapat ${ }^{1}$, Kanokporn Chimplee ${ }^{1}$, Ratana Rujirakul ${ }^{2}$, Soraya \\ Kaewpitoon ${ }^{2,3,4}$, Natthawut Keawpitoon ${ }^{2,3,5 *}$
}

\begin{abstract}
This cross-sectional descriptive and qualitative study was aimed to study the people participation and their approaches toward the human carcinogenic liver fluke, Opisthorchis viverrini, prevention and control in Ban Chaun sub-district administrative organization (BCSAO) and Bamnet Narong sub-district municipality (BNSM), Bamnet Narong district, Chaiyaphum Province, Thailand between June 2013 and February 2014. Participants were purposive selected, included chiefs of sub-district administrative organizations, sub-district municipalities, sub-district health promotion hospitals (SHPHs), heads of village, and a further sample was selected with a multistage random sampling for public health volunteers, and villagers. The pre-designed questionnaire contained items for individualized status and the participatory steps of sharing ideas, decision-making, and planning, procession, evaluation, and mutual benefit, for the project $O$. viverrini prevention and control (POPC). In-depth interviews were used for collection of need approaches to POPC. With 375 participants who completed the questionnaire, it was found that people had a high level regarding to participate in the POPC, particularly in the process stage $(\overline{\mathbf{X}}=3.78$, S.D. $=0.56)$, but the lowest level was found in sharing ideas, decision making, and planning step $(\overline{\mathbf{X}}$ $=3.65$, S.D. $=0.63$ ). By comparison, participant status and organization did not significantly differ with people participation. In each step, Ban Chaun sub-district had a high level of participation in the step of sharing ideas, decision making, and planning toward POPC, more than Bamnet Narong sub-district municipality $(\mathrm{t}=\mathbf{2 . 2 0}$, p=0.028). Approaches for POPC in Ban Chaun sub-district and Bamnet Narong sub-district municipality included requirements for budget support, annual campaigns for liver fluke prevention and control, campaign promotion, risk group observation, home visiting, community rules regarding reducing raw fish consumption in their communities, and a professional public health officer for working in their communities, BCSAO, BNSM, and SHPH, for $O$. viverrini prevention and control. This study indicates that people realize that eradication of the liver fluke needs a continuous people participation for $O$. viverrini prevention and control in their communities.
\end{abstract}

Keywords: People participation - Opisthorchis viverrini - prevention and control - Thailand

Asian Pac J Cancer Prev, 17 (1), 177-181

\section{Introduction}

The Opisthorchis viverrini; carcinogenic liver fluke, is an endemic in the Lower Mekong Basin, including Thailand, Lao People's Democratic Republic, Cambodia and central Vietnam (Sripa et al., 2010). The underestimate of infections are considered, more than 10 million people are infected with $O$. viverrini in Thailand and Lao PDR (Sithithaworn et al., 2012). In Thailand, it is estimated that 6 million people are infected with the $O$. viverrini (Jongsuksuntikul and Imsomboon, 2003). This figure indicated that it is a serious public health problem in Thailand, particularly in northeastern and northern region (Kaewpitoon et al., 2008; Sripa et al., 2010). The O.viverrini infection is associated with hepatobiliary diseases including hepatomegaly, cholangitis, cholecystitis, and gallstones (Harinasuta and Vajrasthira 1960; Thamavit et al., 1978; Harinasuta et al., 1984). Recently, O viverrini has been classified as Type 1 carcinogens by the International Agency for Research on Cancer, World Health Organization (WHO) (IARC, 1994).

A community-level health education campaign been conducted since late 1950s. O. viverrini control has been started as a small scale helminthiasis control program in some high risk areas. A large scale has been started, the program is operated in some provinces of the central and all provinces of the northeast and north of Thailand. The main strategies for liver fluke control comprise three interrelated approaches, namely stool examination and treatment of positive cases with praziquantel for

${ }^{1}$ Social Sciences for Development Program, Faculty of Humanities and Social Sciences, Nakhon Ratchasima Rajabhat University, ${ }^{4}$ Suranaree University of Technology Hospital, Institute of Medicine, Suranaree University of Technology, ${ }^{2}$ Parasitic Disease Research Unit, ${ }^{3}$ School of Family Medicine and Community Medicine, ${ }^{5}$ Faculty of Public Health, Vongchavalitkul University, Nakhon Ratchasima, Thailand*For correspondence: natthawut.k@hotmail.com 
eliminating human host reservoir, health education for a promotion of cooked fish consumption to prevent infection, and improvement of hygienic defecation for the interruption of disease transmission (Jongsuksantikul and Imsomboon, 2003; Sithithaworn et al., 2012). The O.viverrini infection in Thailand was the first reported in 1955 (Sadun) and many strategies has been operated over period 1955-2000, the national prevalence of $O$. viverrini infection had fallen from $63.6 \%$ to $9.6 \%$ but the high prevalence rate is still found in the rural communities of provinces, Northeast (Sithithaworn et al., 2012). In addition, the high mortality rate of CCA was reported in the northeast areas where found frequently of $O$. viverrini infection (Sripa et al., 2010). Mortality rate of liver cancer and $O$. viverrini infection rate in different regions of Thailand has been reported that Chaiyaphum province has 30.14-44.31 per 100,000 populations. Eradication of the fluke and identification of high-risk populations are urgently needed (Sripa and pairojkul, 2008). In addition, $O$. viverrini infection has been reported that $17.6 \%$ prevalence of infection in Chaiyaphum province (Sitthithaworn et al., 2012). The national control program seems to have had little impact in many of these areas, and it has been difficult to make precise assessments of the overall effectiveness of the program. Therefore there is a need for a community-based approach to prevent infection with the parasite, ideally involving as many players as possible (Duangsong et al., 2013). Therefore, people participation and their needs toward $O$. viverrini prevention and control in Ban Chaun sub-district and Bamnet Narong sub-district municipality, Bamnet Narong district, Chaiyaphum Province, Thailand, is performed between June 2013 and February 2014. This basic knowledge is able useful for further planning of prevention and control in that areas including similarly communities.

\section{Materials and Methods}

A cross-sectional survey was conducted in Ban Chuan sub-district and Bamnet Narong sub-district municipality, of Bamnet Narong district. Bamnet Narong is a district in the southwestern part of Chaiyaphum province, northeastern Thailand. The district is covered area 560.3 $\mathrm{km}^{2}$ (216.3 sq mi), 54,750 populations, and density $97.7 / \mathrm{km}^{2}$ (253/sq mi). Neighboring districts are (from the west clockwise) Thep Sathit, Sap Yai, Chatturat of Chaiyaphum province, Dan Khun Thot and Thepharak of Nakhon Ratchasima province. The district is subdivided into 7 sub-districts, which are further subdivided into 88 villages. There are two townships (municipality) within the district - Bamnet Narong covers parts of Ban Chuan sub-district, and Ban Phet Phu Khiao parts of Ban Phet sub-district. There are further 7 sub-district administrative organizations (SAO), included Ban Chuan, Ban Phet, Ban Tan, Hua Thale, Khok Roeng Rom, Ko Manao, Khok Phet Phatthana (Royal Gazette, 1939). Ban Chuan sub-district administrative organization (BCSAO), and Bamnet Narong sub-district municipality (BNSM), are located in Ban Chuan sub-district where is approximately 5 kilometer from Bamnet Narong district, 60 kilometer from Chaiyaphum province, and 260 kilometer from Bangkok. BCSAO and BNSM are further 17 and 8 villages, respectively. Both of organizations, has 10,754 populations. Participant who had over 15 years old included head of community (BCSAO, BNSM, villages), represents from sub-district health promotion hospital (SHPH), and villagers, were calculated by sample size determination using Krejcie and Morgan table (1970). Of 375 participants, is purposive selected (head of villages, members of BCSAO and BNSM), and multi-stage random sampling (village health volunteer and villagers), following Table 1.

Pre-designed questionnaire contained part 1 ; participant status, part 2; participatory question regarding to participate the project of $O$. viverrini prevention and control: 30 questions with sharing idea, decision making, and planing, procession, evaluation, and mutual benefit. The questionnaire was 5 rating scale; highest, high, moderate, low, and lowest. Reliability of questionnaire was analyzed, Cronbach alpha coefficient $=0.847$, sharing idea, decision making, and planing $=0.835$, procession $=0.784$, evaluation $=0.818$, and mutual benefit $=0.788$. For interpret result; 4.51-5.00; highest level, 3.51-4.50; high level, 2.513.50; moderate level, 1.51-2.50; low level, and 1.00-1.50; lowest level of partipation. Independent T-test and Oneway ANOVA were used for comparison of participation and pattern of organization, and status, respectively. For study the approach to develop the people participation toward $O$. viverrini prevention and control by using indepth interview in 8 participants who were purposive selected from 2 SHPH, 1 head of village, 1 BCSAO, 1 BNSM, and 3 village health volunteers. The questions containing the step of people participation particularly sharing idea, decision making, and planing, procession, evaluation, and mutual benefit step. Quality data analysis using content analysis

\section{Results}

Of 375 participants was completed the questionnaire and found that the majorities of participant were villagers $(67.46 \%)$ and followed by the head of BCSAO, BNSM,

Table 1. Sample Size Determination for Study

\begin{tabular}{|c|c|c|c|c|c|c|}
\hline \multirow[t]{2}{*}{ Status } & \multicolumn{2}{|c|}{ BNSM } & \multicolumn{2}{|c|}{ BCSAO } & \multicolumn{2}{|c|}{ Total } \\
\hline & Population & Sample size & Population & Sample size & Population & Sample size \\
\hline Head/member & 20 & 20 & 51 & 51 & 71 & 71 \\
\hline Village health volunteer & 227 & 24 & 177 & 27 & 404 & 51 \\
\hline Villagers & 5,676 & 121 & 4,603 & 132 & 10,279 & 253 \\
\hline Total & 5,923 & 165 & 4,831 & 210 & 10,754 & 375 \\
\hline
\end{tabular}


and SHPH, and village health volunteers, respectively. The majority of participant was habitat in Ban Chaun sub-district (56\%) (Table 2). Level of people participation in POCP, was analyzed and found that people had a high level of all stage of participation $(\overline{\mathbf{X}}=3.71$, S.D. $=0.52)$. The high level was found in the activity of procession $(\overline{\mathbf{X}}=3.78$, S.D.=0.6), followed by evaluation and mutual

Table 2. Participant Characteristics by Status and Pattern of Community Organization

\begin{tabular}{lrl}
\hline Characteristics & No. (N=375) & $\%$ \\
\hline Status & & \\
Head of Community & 71 & 18.94 \\
Village Health Volunteer & 51 & 13.6 \\
Villagers & 253 & 67.46 \\
Pattern of local administrative organization & & \\
Sub-district municipality & 165 & 44 \\
Sub-district administrative organization & 210 & 56 \\
\hline
\end{tabular}

Table 3. Level of people participation toward $O$. viverini prevention and control in Bamnet Narong district, Chaiyaphum province, Thailand between June 2013 and February 2014

\begin{tabular}{lclc}
\hline People Participation & $\overline{\mathbf{X}}$ & S.D. & Interpretation \\
\hline Sharing idea, & 3.65 & 0.63 & high \\
decision making, and planning & & \\
Procession & 3.78 & 0.56 & high \\
Evaluation & 3.72 & 0.6 & high \\
Mutual benefit & 3.71 & 0.67 & high \\
\hline Mean & 3.71 & 0.52 & high \\
\hline
\end{tabular}

benefit (Table 3). A comparison between participation and status regarding $O$. viverrini prevention and control was measured and found that there was not statistical significant different in all status of participant $(\mathrm{F}=1.26$, $\mathrm{p}=0.285$ ) (Table 4). Meanwhile, a comparison of people participation in different place, was measured and found that there was not statistical significant different in both of local administrative organization $(\mathrm{t}=1.89, \mathrm{p}=0.06)$. However, people participation was statistical significant different regarding sharing idea, decision making, and planning of POPC. Participant from BCSAO had a higher participated than BNSM, $(\mathrm{t}=2.20, \mathrm{p}=0.028)$ (Table 5).

The approaches to develop the people participation of $O$. viverrini prevention and control, was interviewed and included sharing idea, decision making, and planning step; (1) budget support by BCSAO to SHPH for O. viverrini screening including related activities (2) budget planning by SHPH for health education campaign (3) budget planning for annual from related organization particularly district hospital, provincial public health office, and provincial administrative organization. Procession step; (1) people participation of campaign for liver fluke prevention and control (2) annual campaign for liver fluke prevention and control by SHPH and stakeholder, and should be continuous activities. Evaluation step; (1) promotion of people participation in the activities evaluation of behavior regarding to liver fluke, (2) Observation of risk group, by health officer and represent, and (3) Evaluation and assessment of each projects regarding liver fluke prevention and control by health officer and represent. Mutual benefit step; (1) home visiting by health officer and should integrate the knowledge regarding to liver fluke for improve their perception, (2) community rule regarding to

Table 4. Comparison between participation and status regarding $O$. viverrini prevention and control in Bamnet Narong district, Chaiyaphum porvince, Thailand

\begin{tabular}{|c|c|c|c|c|c|c|c|c|}
\hline \multirow[t]{3}{*}{ People participation } & \multicolumn{6}{|c|}{ Status } & \multirow[t]{3}{*}{$\mathrm{F}$} & \multirow[t]{3}{*}{ p-value } \\
\hline & \multicolumn{2}{|c|}{$\begin{array}{c}\text { Head } \\
(\mathrm{n}=71)\end{array}$} & \multicolumn{2}{|c|}{$\begin{array}{l}\text { Village health volunteer } \\
\qquad(\mathrm{n}=51)\end{array}$} & \multicolumn{2}{|c|}{$\begin{array}{l}\text { Villagers } \\
(\mathrm{n}=253) \\
\end{array}$} & & \\
\hline & $\overline{\mathbf{X}}$ & S.D. & $\overline{\mathbf{X}}$ & S.D. & $\overline{\mathbf{X}}$ & S.D. & & \\
\hline Sharing idea, decision making, and planning & 3.59 & 0.637 & 3.68 & 0.672 & 3.66 & 0.619 & 0.43 & 0.647 \\
\hline Procession & 3.75 & 0.504 & 3.79 & 0.577 & 3.78 & 0.577 & 0.11 & 0.893 \\
\hline Evaluation & 3.6 & 0.609 & 3.85 & 0.591 & 3.72 & 0.599 & 2.52 & 0.081 \\
\hline Mutual benefit & 3.61 & 0.698 & 3.82 & 0.741 & 3.71 & 0.647 & 1.41 & 0.243 \\
\hline Total & 3.64 & 0.519 & 3.79 & 0.552 & 3.72 & 0.508 & 1.26 & 0.285 \\
\hline
\end{tabular}

statistical significant, 0.05

Table 5. Comparison between participation and pattern of local administrative organization place regarding $O$. viverrini prevention and control in Bamnet Narong district, Chaiyaphum porvince, Thailand

\begin{tabular}{|c|c|c|c|c|c|c|}
\hline \multirow[t]{3}{*}{ People participation } & \multicolumn{4}{|c|}{$\underline{\text { Pattern of local administrative organization }}$} & \multirow[t]{3}{*}{$\mathrm{t}$} & \multirow[t]{3}{*}{$\mathrm{p}$} \\
\hline & \multicolumn{2}{|c|}{$\begin{array}{l}\text { Bamnet Narong SM } \\
(\mathrm{n}=165)\end{array}$} & \multicolumn{2}{|c|}{$\begin{array}{l}\text { Ban Chuan SAO } \\
\quad(n=210) \\
\end{array}$} & & \\
\hline & $\overline{\mathbf{X}}$ & S.D. & $\overline{\mathbf{X}}$ & S.D. & & \\
\hline Sharing idea, decision making, and planning & 3.57 & 0.65 & 3.71 & 0.61 & $2.20 *$ & 0.028 \\
\hline Procession & 3.72 & 0.6 & 3.82 & 0.53 & 1.67 & 0.096 \\
\hline Evaluation & 3.66 & 0.59 & 3.76 & 0.61 & 1.53 & 0.127 \\
\hline Mutual benefit & 3.67 & 0.7 & 3.74 & 0.64 & 0.98 & 0.328 \\
\hline Total & 3.66 & 0.54 & 3.76 & 0.5 & 1.89 & 0.06 \\
\hline
\end{tabular}

*Statistical significant, 0.05 


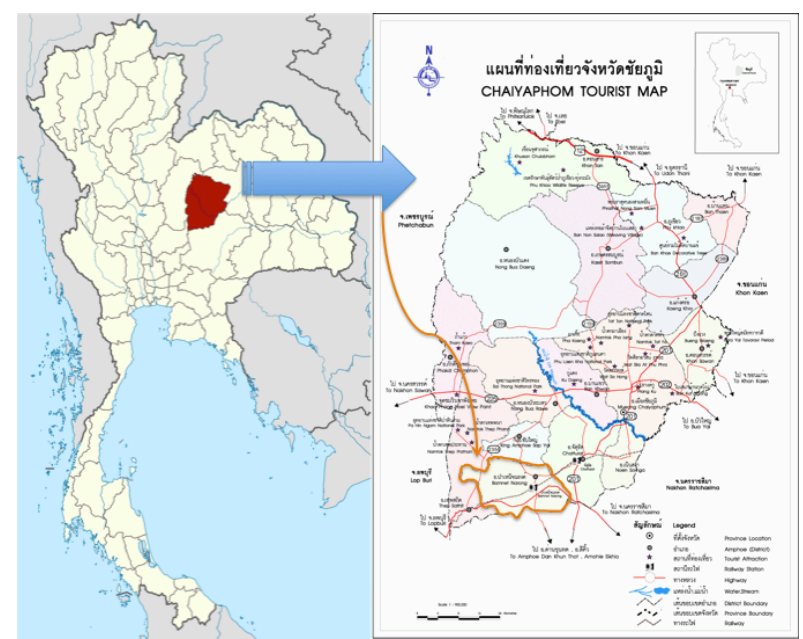

Figure 1. Map of Bamnet Narong district, Chaiyaphum province, Thailand

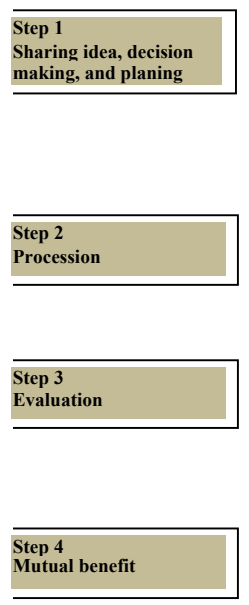

(Sithithaworn et al., 2012). The main strategies for liver fluke control comprise three interrelated approaches, namely stool examination and treatment of positive cases with praziquantel for eliminating human host reservoir, health education for a promotion of cooked fish consumption to prevent infection, and improvement of hygienic defecation for the interruption of disease transmission (Jongsuksantikul and Imsomboon, 2003; Sithithaworn et al., 2012).

Recently, document an attempt to assess the best means to prevention on the basis of a community intervention in three villages in northeastern Thailand, with participation of representatives of Health Promotion Hospitals of the Ministry of Public Health with dedicated staff, but also school teachers, independent government sponsored village health volunteers, and housewives responsible for cooking and diet selection. An action plan was followed, allowing detailed discussions of practical proposals, their introduction and then repeated reflection and further proposals at the individual village level (Duangsong et al., 2013). In addition, the liver fluke control programme, named "Lawa model," is now recognized nationally and internationally, and being expanding to other parts of Thailand and neighboring Mekong countries. Challenges to $O$. viverrini disease control, and lessons learned in developing an integrative control program using a community-based, ecosystem approach, and scaling-up regionally based on Lawa as a model are described (Sripa et al., 2015). From a lesson success model, $O$. viverrini prevention and control is approaches in the communities through a community participation, here we described the survey data about people participation in Ban Chuan subdistrict administration organization (BCSAO) and Bamnet Narong sub-district municipality (BNSM) where are located in Bamnet Narong district, Chaiyaphum province.

Chaiyaphum province has reported that is a highly risk area of $O$. viverrini and cholangiocarcinoma. Mortality rate of liver cancer and $O$. viverrini infection rate in Chaiyaphum province was rank between 30.1444.31 per 100,000 populations. Eradication of the fluke and identification of high-risk populations are urgently needed (Sripa and pairojkul, 2008). Up to date, $O$. viverrini infection has reported that $17.6 \%$ prevalence of infection in Chaiyaphum province (Sitthithaworn et al., 2012). A survey of people participation and their need is concerned. People participation had a high level in all step of sharing idea, decision making, planning, procession, evaluation, and mutual benefit, reading to the project of $O$. vierrini prevention and control in their communities. Unfortunately, O. vierrini infection has not been detected, therefore these could be not indicate that success or not in this communities. However, the data show a positive attitude to eradicate live fluke in both communities organization. In addition, their need is in-depth interviewed and found that budget support, annual campaign for liver fluke prevention and control, campaign promotion, risk group observation, home visiting, community rule regarding to stop the raw fish consumption in their communities, and need a professional of public health officer for working in their communities, BCSAO, BNSM, and SHPH, are their approaches to $O$. found in the rural communities of provinces, Northeast 
viverrini prevention and control.

In conclusion, these data indicates communities need to eradicate a serious problem in their communities by themselves and collaboration with public health officer, including members from SAO and SM, may advantage and get a new success model. Furthermore, screening of $O$. viverrini and cholangiocarcinoma are required, and follow up regarding to their activities and participation is measured.

\section{Acknowledgements}

Special thanks to all staff of Ban Chuan sub-district administration organization and Bamnet Narong subdistrict municipality for their collaboration and assistance, many thanks to staff of Social Sciences for Development Program, Faculty of Humanities and Social Sciences, Nakhon Ratchasima Rajabhat Univerisity, Thailand, for their comment and suggestion.

\section{References}

Duangsong R,Promthet S, Thaewnongiew K (2013).Development of a community-based approach to opisthorchiasis control. Asian Pac J Cancer Prev, 14, 7039-43.

Harinasuta C, Vajrasthira S (1960). Opisthorchiasis in Thailand. Am J Trop Med Hyg, 54, 100-5.

Harinasuta T, Riganti M, Bunnag D (1984). Opisthorchis viverrini infection: pathogenesis and clinical features. Arzneimittelforschung, 34, 1167-9.

IARC. (1994). Infection with liver flukes (Opisthorchis viverrini, Opisthorchis felineus and Clonrochis sinensis). IARC Monogr Eval Carcinog Risks of Hum, 61, 121-75.

Jongsuksuntigul P, Imsomboon T (2003). Opisthorchiasis control in Thailand. Acta Trop, 88, 229-32.

Kaewpitoon N, Kaewpitoon SJ, Pengsaa P(2008). Opisthorchiasis in Thailand: review and current status. World J Gastroenterol, 14, 2297-302.

Krejcie RV, Morgan DW (1970). Determining sample size for research activities. Edu Psychol Measur, 30, 607-10.

Royal Gazette (1939). Royal gazette of district, sub-district in Thailand, 354-64.

Sadun EH (1995). Studies on Opisthorchis viverrini in Thailand. Am J Hyg, 62, 81-115.

Sithithaworn P, Pipitgool V, Srisawangwong T, et al., (1997). Seasonal variation of Opisthorchis viverrini infection in cyprinoid fish in north-east Thailand: implications for parasite control and food safety. Bull WHO, 75, 125-31.

Sithithaworn P, Andrews RH, Nguyen VD, et al (2012). The current status of opisthorchiasis and clonorchiasis in the Mekong Basin. Parasitol Int, 61, 10-6.

Sripa B, Kaewkes S, Intapan PM, et al (2010). Food-borne trematodiases in Southeast Asia: epidemiology, pathology, clinical manifestation and control. Adv Parasitol, 72, 305-50.

Sripa B, Pairojkul C (2008). Cholangiocarcinoma: lessons from Thailand. Curr Opin Gastroenterol, 24, 349-56.

Sripa B, Tangkawattana S, Laha T, et al (2015). Toward integrated opisthorchiasis control in northeast Thailand: the Lawa project. Acta Trop, 141, 361-7.

Thamavit W, Bhamarapravati N, Sahaphong S, et al (1978). Effects of dimethylnitrosamine on induction of cholangiocarcinoma in Opisthorchis viverrini-infected Syrian golden hamsters. Cancer Res, 38, 4634-9.

Vichasri S, Viyanant V, Upatham ES (1982). Opisthorchis viverrini: intensity and rates of infection in cyprinoid fish from an endemic focus in northeast Thailand. Southeast Asian J Trop Med Public Health, 3, 138-41.

Wykoff DE, Chittayasothorn K, Winn MM (1966). Clinical manifestation of Opisthorchis viverrini infection in Thailand. Am J Trop Med Hyg, 15, 914-8. 